\title{
NOTAS SOBRE LOS ELEMENTOS LÉXICOS HISPÁNICOS DE FECHA RECIENTE EN RUMANO
}

\author{
Notes on the Hispanic lexical elements of recent date in Romanian
}

Iulia Nica*

\begin{abstract}
RESUMEN
El contacto entre el rumano y el español se ha intensificado en el período postcomunista, de mano con las nuevas realidades socio-políticas de Rumanía y la migración endémica hacia España. En este artículo, se analiza un inventario léxico hispánico de fecha reciente en el rumano intraterritorial, extraído de varios diccionarios, y se señalan algunos fenómenos más llamativos.
\end{abstract}

Palabras clave: rumano, español, contacto lingüístico, préstamo.

\begin{abstract}
The contact between the Romanian and the Spanish languages intensified in the post-communist years, as a result of both the new socio-political circumstances of Romania and the endemic Romanian migration to Spain. It is analyzed a Hispanic lexical inventory (extracted from several dictionaries) of recent date in the intraterritorial Romanian and it is pointed out some striking phenomena.
\end{abstract}

Key Words: Romanian, Spanish, language contact, borrowing and loanword.

\section{Introducción}

Se propone en este trabajo investigar los elementos léxicos hispánicos que han hecho su aparición en el rumano intraterritorial después de $1990 .^{\dagger}$ Este tema no ha sido muy estudiado tal como se constata en la bibliografía (Dimitrescu, 2007a, 2007b, 2014b; Stăncioi-Scarlat, 2010; Lăzărescu, 2013). ${ }^{\ddagger}$ En concreto, es de interés los siguientes aspectos: la relación de los

\footnotetext{
* Doctora en Lingüística Computacional (Universidad de Barcelona), profesora de la Universidad "Alexandru Ioan Cuza" de Iasi, Rumanía - Universidad de Sevilla, España. Correo electrónico: nica@ us.es Recepción: 21/12/2016 Aceptación: 20/11/2017

${ }^{\dagger}$ No se cubren los fenómenos de contacto producidos en el ámbito de la comunidad rumana de España, que se han estudiado en otra ocasión: Nica, Iulia. (2013). Nuevos contactos rumano-romance: algunos fenómenos de interferencia. En Iulian Boldea (Ed.), Studies on Literature, Discourse and Multicultural Dialogue (pp. 809819). Tîrgu-Mureș: Arhipelag XXI Press. Recuperdo de http://www.upm.ro/ldmd/LDMD01/Lds/Lds\%2001\%2091.pdf

‡ Se añaden algunas comunicaciones en conferencias: Biriș, Gabriela. (2007). Elementos léxicos hispánicos en el rumano actual. Le congrès de la Société de Linguistique Romane (XXV CILPR), Innsbruck (Leopold-FranzensUniversität), Autriche, 3-8 septembre de 2007; Biriș, Gabriela. (2009). Sobre la dinámica del préstamos hispánico en el rumano. Simposio TID: Traducción e Identidad Diaspórica, Alicante, 12-14 noiembrie de 2009; Biriș,
} 
préstamos con el español (patrimoniales o importados), su vía de acceso al rumano (directa, indirecta o múltiple) y su adaptación al sistema de la lengua rumana, los dominios semánticos a los que pertenecen, las tendencias de momento en el contacto lingüístico rumano-español. Este artículo se considera como un estudio preliminar y no un trabajo exhaustivo. La investigación se desarrolla principalmente sobre un inventario léxico creado a partir de varias fuentes, pero se amplía para cuestiones específicas con un corpus de diccionarios. ${ }^{\S}$

\section{Marco teórico e histórico}

La terminología empleada con referencia a los vocablos procedentes de otras lenguas es a menudo vacilante y ambigua; se añaden ligeras diferencias entre las lingüísticas rumana e hispánica. Se prefieren así obviar términos como "neologismo", "préstamo propiamente dicho" y “xenismo", "hispanismo”, “españolismo”, "palabra española”. Se hablará indistintamente de “elementos léxicos" o "préstamos recientes" hispánicos, de España y de Hispanoamérica, incluyendo aquí las unidades fraseológicas y los sentidos nuevos. Se hará la distinción entre préstamos directos (o inmediatos), incorporados del español mismo, e indirectos (o remotos), que han entrado en rumano a través de otros idiomas, así como entre préstamos adaptados y no adaptados.

La determinación de la etimología de algunas palabras rumanas es una tarea dificultada por los numerosos y complejos contactos lingüísticos que han surgido a lo largo de la historia: los préstamos pueden haber entrado desde varias lenguas, en la misma época o a distancia en el tiempo y en el espacio. Para la explicación del origen de una palabra y de todos sus sentidos a través de varios étimos, la lingüística rumana usa el concepto de "etimología múltiple" (Graur, 1950).** Se atribuye etimología múltiple a un gran número de palabras del rumano (Sala, 2001, s.v. etimologie multiplă).

Son relevantes para el actual estudio algunas de las características que distinguen al rumano del español: dos vocales centrales más (/ə/, escrita $\breve{a}$, y /ił/, escrita $\hat{a}$ o $\hat{\imath}$ ), ausencia de algunas consonantes $(/ \lambda /, / \mathrm{n} /, / \theta /, / \mathrm{r} /)$ y presencia de otras (/d子/ (en $g e, g i), / 3 /(j), / J /(s), /$ ts $/(t)$,

\footnotetext{
Gabriela y Madrona Fernández, Alberto. (2008). Neologismos de origen hispano en rumano. CINEO 2008 I Congreso Internacional de Neología en las lenguas románicas, Barcelona, 07-10 Mayo de 2008.

$\S$ A continuación, se emplean las siguientes abreviaturas: $m$. (masculino), f. (femenino), $n$. (neutro), sing. (singular), pl. (plural).

*** Alexandru Graur. (1950). Etimologie multiplă. En Studii şi cercetări lingvistice I (1), 22-34.
} 
$/ \mathrm{v} /(v), / \mathrm{z} /(z))$, reglas ortográficas distintas $(h[\mathrm{~h}], j[3], z[\mathrm{z}], c e$ [tge $], c i[\mathrm{tgi}]$, che [ke], chi [ki], ge [dze], gi [ḋi], ghe [ge], ghi [gi]), así como un inventario diferente de letras, dígrafos y trigrafos ( $\sin l l, \tilde{n}$, gue, gui, que, qui, güe, güi y con $\breve{a}$ [ə], $\hat{a}[\mathrm{i}], \hat{\imath}[\mathrm{i}], s\left[\int\right], t$ [ts], ghe [ge], ghi [gi]), no señalación gráfica del acento tónico, tres géneros en el sustantivo (masculino, con terminación consonántica o - $u,-e,-\mathrm{i}$; femenino, con las terminaciones -ă, - $e$ o - $a$ tónica; y neutro, con terminaciones similares al masculino), plural vocálico (m. - $i$, f. - $e$, n. -uri/-e), artículo definido enclítico (m./n. sing. -(u)l/-le, f. sing. -(u)a, m. pl. - $i$, f./n. pl. -le), declinación sintética (dos declinaciones distintas, con artículo definido o sin él).

El rumano es considerado una de las lenguas más "acogedoras" de Europa (Lombard, 1969) $)^{\dagger \dagger}$ por su apertura hacia los préstamos, lo que se refleja en la composición heterogénea del vocabulario. Sin embargo, en paralelo, actúa una gran fuerza de asimilación, fonética y gramatical. La adaptación fonética es parcial y más lenta cuando intervienen sonidos inexistentes en rumano, que son aproximados con otros cercanos del sistema propio; afecta sobre todo los sonidos o grupos de sonidos finales, con papel morfológico. Muchos préstamos más antiguos han cambiado la grafía para ponerla de acuerdo con la pronunciación; a veces, al revés, se ha impuesto la forma escrita en la pronunciación. La lengua culta actual tiende a conservar la ortografía y la pronunciación originarias, aun cuando la correspondencia entre estas contradice las reglas ortográficas rumanas; se puede oscilar entonces entre seguir la escritura o la pronunciación de la lengua fuente. La adaptación morfológica es requerida por las necesidades de la morfosintaxis rumana y suele ser rápida. En el caso de los sustantivos, el proceso empieza con la posposición del artículo definido y sigue con las desinencias de plural. La incorporación en los géneros depende de la forma, luego del sentido: serán femeninos los nombres con final típica para este género; en caso contrario, serán masculinos si designan seres de sexo masculino y neutros si no lo hacen (Sala, 2001, s.v. ospitalitate, s.v. neologism; Dimitrescu, 1985 y 1986).

A partir del siglo XVIII, el rumano recibió una importante influencia latino-románica, lo

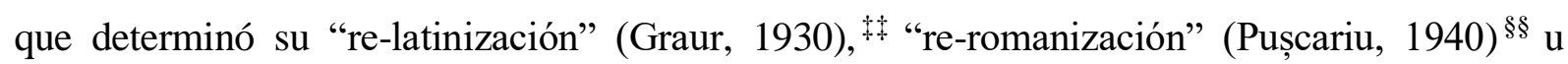
“occidentalización románica” (Sala, 2001, s.v. relatinizare y s.v. reromanizare). Debido a la

\footnotetext{
${ }^{+\dagger}$ Alf Lombard. (1969). Le vocabulaire d'emprunt. Questions de principe. Actes du Xe Congrès International des Linguistes. Bucureşti (vol. I), 645-649.

\# Alexandru Graur. (1930). Relatinizarea limbii. En Adevărul, 20 august 1930.

$\S \S$ Sextil Pușcariu. (1940). Limba română, I. Privire generală. București.
} 
distancia geográfica y a la influencia menos marcada de la cultura española en Europa después del Siglo de Oro, las relaciones rumano-hispánicas fueron sin embargo esporádicas hasta medidados del siglo XIX. El desarrollo cultural de Rumanía y los estrechos lazos con Francia favorecieron desde entonces el conocimiento, si bien mediato, del mundo iberoamericano. El contacto se avivó en la segunda mitad del siglo pasado, con la explosión de los mass media, las traducciones literarias y un mayor interés por las realidades político-culturales de la Península Ibérica o Hispanoamérica. La dimensión reducida de los contactos se refleja en los raros estudios que se les dedican (Iordan y Georgescu, 1964; Tudorică, 1966; Dumitrescu, 1970; Şandru Olteanu, 1972; Şandru Olteanu, 1978; Toma, 1978; Avram, 1982; Biriș, 2007).***

Estimaciones de 1964, 1978 y 1985-1986 (Macrea, 1968; †† apud Șandru Olteanu, 1978; Şandru Olteanu, 1978; Dimitrescu, 1985 y 1986) hablan de aproximadamente 150 vocablos hispánicos, escasos en comparación con los procedentes del latín, del italiano y sobre todo del francés: entre 20 y 30 préstamos directos frente a unos 120 entrados a través del francés, del italiano, del neogriego, del turco y del alemán. Los elementos españoles son cultos, estilísticos

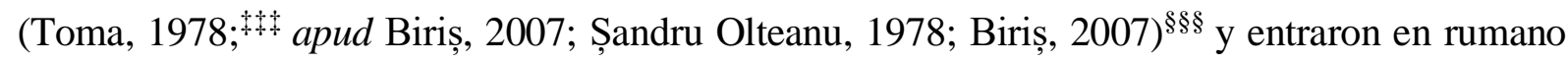
generalmente a través de un contacto a distancia (Iordan, 1973, p. 134), ${ }^{* * * *}$ sea escrito traducciones, libros en original, prensa-, sea oral - películas, televisión, radio- (Dimitrescu, 1985 y 1986). Șandru Olteanu (1978) recoge un grupo de 27 palabras incorporadas relativamente poco antes al rumano, también presentes en otras lenguas europeas. Los vocablos designan realidades del espacio hispánico, procedentes de dominios como música y baile, química, zología y botánica, unidades de medida, circulación, arquitectura y construcciones, vestimenta. Trece de estos son integrados al rumano (nueve de uso periférico, cuatro con ampliación semántica y más frecuentes);

\footnotetext{
**** Iorgu Iordan y P. Al. Georgescu. (1964). Los estudios hispánicos en Rumania. Bucureşti: Societatea Română de Lingvistică Romanică; Olga Tudorică. (1966). Preocupări de limbă spaniolă la Mihail Kogălniceanu. En Cercetări de Lingvistică, XI (1), 103-115; Domnița Dumitrescu. (1970). Limba spaniolă în opera de lingvist şi filolog a lui B. P. Hasdeu. En Studii de Hispanistică (pp. 39-50). Bucureşti: Societatea Română de Lingvistică Romanică; Tudora Şandru Olteanu. (1972). O lucrare spaniolă din secolul al XIX-lea despre limba română. En Philologica II, 27-40; Elena Toma. (1978). Observații asupra lexicului de origine spaniolă din româna actuală. En Etudes romanes III. Hommage à Iorgu Iordan (pp. 469-477). Bucureşti: Societatea Română de Lingvistică Romanică; Gabriela Biriș. (2007). Hispanisme în Impresii asupra literaturii spaniole. En Analele Universităţii din Craiova, Ştiinţe Filologice, Limbi Străine Aplicate III (1-2), 26-31. Recuperado de http://cis01.central.ucv.ro/analele_universitatii/limbi_straine_aplicate/2007/volum.pdf

†ो Dimitrie Macrea. (1968). La terminologie scientifique et technique dans la langue roumaine contemporaine. En Antonio Quilis et al. (Eds.), Actas del XI Congreso Internacional de Lingüística y Filología Románica, Madrid, 1964, (vol. II: 722).

\#* Op. cit., nota $* * *$.

$\S \S \S$ Op. cit., nota ***.

***** Iorgu Iordan. (1973). Bilingvism în domeniul romanic. En Studii şi cercetări lingvistice, XXIV(2), 123-135.
} 
catorce tienen forma no adaptada (solo diez son incluidos en los diccionarios). En cuanto a la vía de entrada en rumano, quince tienen etimología directa, de los cuales catorce, múltiple. Dimitrescu $(1985,1986)$ analiza las unidades léxicas españolas inventariadas después de 1960 en la prensa por el DCR (1982). ${ }^{\dagger \dagger \dagger}$ De los diecisiete vocablos, quince no son adaptados y doce provienen directamente del español, cinco con etimología múltiple. Se observa una tendencia hacia la conservación de las características gráficas y fonéticas originarias, aunque las palabras pasen por una lengua intermediaria: $\tilde{n}$ (vicuña), $j[\mathrm{~h}]$ (jota), nombres femeninos en -a (seguidilla, jota), plurales sigmáticos (patios, avenidas), se añadirían nombres en -o (patio, poncho).

Los cambios políticos que experimentó Rumanía a partir de 1989 han creado una serie de circunstancias dinamizadoras para la entrada de elementos léxicos hispánicos en rumano: apertura del país hacia el exterior, libertad de expresión, incorporación a la Unión Europea en 2007, movilidad de personas y emigración endémica a España especialmente a partir de 2000. Se añaden otros factores favorables a los préstamos, como el incremento del español en la educación formal, la difusión de telenovelas latinoamericanas, la apertura de restaurantes españoles y latinoamericanos en Rumanía o los éxitos de la música iberoamericana y del fútbol español a nivel mundial. En líneas generales, el contacto entre el español y el rumano fue principalmente a distancia en los años 90, pero más inmediato y mucho más intenso después de 2000.

\section{Estudio empírico}

Los datos que se analizan en este artículo proceden fundamentalmente de diccionarios, medios de comunicación masiva e internet, fuentes que reflejan fielmente el estado de la lengua. Elaborado a partir de la prensa y últimamente también de la red, el Diccionario de palabras recientes (DCR), con las ediciones de 1997 y 2013, ha resultado particularmente útil al datar, para cada entrada, la primera documentación al igual que los demás ejemplos:

DCR2: Florica Dimitrescu. (1997). Dicționar de cuvinte recente (2. a edición). București: Logos.

\footnotetext{
${ }^{+++\dagger}$ Florica Dimitrescu. (1982). Dicţionar de cuvinte recente (DCR). București: Editura Albatros.
} 
DCR3: Florica Dimitrescu, Alexandru Ciolan, Coman Lupu. (2013). Dicționar de cuvinte recente (3. a edición). București: Logos.

El Diccionario de palabras y sentidos recientes (DCSR, 2014) contiene vocablos de varios registros, aparecidos después del comunismo:

DCSR: Andrei Dănilă y Elena Tamba. (2014). Dicționar de cuvinte și sensuri recente. București: Litera.

De internet, se han aprovechado el sitio web www.123urban.ro, una colección dinámica de jerga no incluida en los diccionarios, creada en 2005, y http://www.ziare.com, una plataforma de acceso a la prensa rumana y, tangencialmente, otros sitos. Se han añadido unos pocos vocablos que la autora ha detectado personalmente.

Todas estas fuentes han proporcionado, como punto de partida para la investigación, un inventario de 61 elementos léxicos hispánicos entrados en rumano después de 1990:

- Cincuentra procedentes de DCR2, DCR3, DCSR: avocado, bakalao, balsero/balseros, burrito, carambola, castrist, cava, cebiche/ceviche, chili, chorizo, churro, coco, contras, empanadas, enchilada, fajita, gazpacho, gherilă, granadilla, guacamole, guano, guava, hacienda, latino, limetă, maca, Macarena, macho, mallorquin, mate (en la colocación ceai mate), maracas, merengue, milonga, nachos, niño, paella/paëlla, piña colada, piñata, quesadilla, salsa, sandinist/-ă, sangria, tabasco, taco, tapas, telenovelă, tequila, tiki-taka, tortilla (en DCSR, además, tortillas), turron;

- Nueve procedentes de www.123urban.ro: chancho, macho, maricon, mojo, pajero, Maria Ioana 'marihuana' (en la música hip-hop), Querida (apodo para la mujer de un cantante rumano de música latina), a avea cojones 'tener cojones', a da (cuiva) la cucaracea 'tener relaciones sexuales';

- Dos recogidos personalmente: golazo (confirmado en www.ziare.com), partidazo (usado iterativamente en las transmisiones televisivas de balonmano desde los Juegos Olímpicos de Río de Janeiro de 2016).

De manera complementaria, para contrastación, mejor datación e información ortográfica, morfológica o etimológica, se ha explotado como corpus la página https://dexonline.ro, una base de datos que reúne una amplia variedad de diccionarios, 
analizando así otros vocablos fuera del núcleo de partida. Se indica a continuación los recursos más utilizados (ver https://dexonline.ro/surse para referencias completas):

Argou (2007): Dicționar de argou al limbii române.

DE (1993-2009): Dicționar enciclopedic.

DEX'98 (1998): Dicționarul explicativ al limbii române (2. a edición).

DEX'09 (2009): Dicționarul explicativ al limbii române (2. edición).

DN (1986): Dicționar de neologisme.

DOOM2 (2005): Dicționar ortografic, ortoepic și morfologic al limbii române (2. ${ }^{\mathrm{a}}$ edición).

DTM (2010): Dicționar de termeni muzicali.

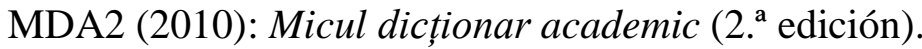

MDN'00 (2000): Marele dicționar de neologisme.

MDN'08 (2008): Marele dicţionar de neologisme (10. ${ }^{a}$ edición).

NODEX (2002): Noul dicționar explicativ al limbii române.

Ortografic (2002): Dicționar ortografic al limbii române.

La comprobación de la etimología hispánica, sobre todo indirecta, y de la vía de entrada en rumano para algunas unidades del inventario de partida ha requerido el recurso a diccionarios suplimentarios: del español (dle.rae.es), francés (http://atilf.atilf.fr; http://www.larousse.fr/dictionnaires/francais), inglés (www.etymonline.com; http://www.merriam-webster.com), italiano (http://dizionari.corriere.it; http://www.garzantilinguistica.it; $\quad$ http://dizionario-italiano.it) y catalán (http://www.diccionari.cat).

Los diccionarios que se han tomado como base en el estudio ofrecen pautas orientatidoras sobre la vía de entrada de las palabras hispánicas en rumano después de 1990 y su grado de adaptación. El DCR2 y el DCR3 recogen 42 palabras, 5 adaptadas (castrist, gherilă, limetă, sandinist/-ăa, telenovelă) y 37 no adaptadas (absolutamente, avocado, bakalao, balsero(s), burrito, cava, cebiche/ceviche, chili, chorizo, churro, coco, contras, empanadas,

\$+ Todas las fuentes han sido consultadas en el intervalo 01-08-2016 al 30-11-2016. 
fajita, gazpacho, guacamole, guava, hacienda, latino, maca, Macarena, macho, mallorquin, mate, merengue, milonga, nachos, paella, quesadilla, salsa, sangria, taco, tapas, tequila, tikitaka, tortilla, turron); por otra parte, 35 con etimología directa (absolutamente, bakalao, balsero(s), burrito, cava, cebiche/ceviche, chorizo, churro, coco, contras, empanadas, fajita, gazpacho, gherilă, guacamole, hacienda, maca, Macarena, macho, mallorquin, mate, merengue, milonga, nachos, paella, quesadilla, salsa, sangria, taco, tapas, telenovelă, tequila, tiki-taka, tortilla, turron); 6 casos con etimología múltiple, español junto con francés, italiano, inglés, portugués, catalán (cava, contras, gherilă, hacienda, macho, taco), y 7 con etimología indirecta (avocado, castrist, chili, gherilă, guava, latino, limetă, sandinist/-ă). Los dos diccionarios permiten delimitar la década 1990-1999 de los años 2000-2012; así, en los 90 han entrado 10 palabras nuevas (avocado, balsero(s), castrist, contras, gherilă, hacienda, Macarena, macho, sandinist/-ă telenovelă), 4 adaptadas (castrist, gherilă, sandinist/-ă, telenovelă) y 6 no adaptadas (avocado, balsero(s), contras, hacienda, Macarena, macho), 7 con etimología directa (balsero(s), contras, gherilă, hacienda, Macarena, macho, telenovelă), múltiple en 4 casos (contras, gherilă, hacienda, macho), y 3 con etimología indirecta (avocado, castrist, sandinist/-ă), mientras que después de 2000 se han incorporado 32 palabras nuevas (absolutamente, bakalao, burrito, cava, cebiche/ceviche, chili, chorizo, churro, coco, empanadas, fajita, gazpacho, guacamole, guava, latino, limetă, maca, mallorquin, mate, merengue, milonga, nachos, paella, quesadilla, salsa, sangria, taco, tapas, tequila, tiki-taka, tortilla, turron), 1 adaptada (limetă) y 31 no adaptadas (absolutamente, bakalao, burrito, cava, cebiche/ceviche, chili, chorizo, churro, coco, empanadas, fajita, gazpacho, guacamole, guava, latino, maca, mallorquin, mate, merengue, milonga, nachos, paella, quesadilla, salsa, sangria, taco, tapas, tequila, tiki-taka, tortilla, turron), además 28 con etimología directa (absolutamente, bakalao, burrito, cava, cebiche/ceviche, chorizo, churro, coco, empanadas, fajita, gazpacho, guacamole, maca, mallorquin, mate, merengue, milonga, nachos, paella, quesadilla, salsa, sangria, taco, tapas, tequila, tiki-taka, tortilla, turron), múltiple en 2 casos (cava, taco), y 4 con etimología indirecta (chili, guava, latino, limetă). Según el DCR2 y el DCR3, la proporción entre las voces adaptadas y no adaptadas es por lo tanto de 5:37, o sea, aproximadamente 1:7,5, per total (pero 4:6, o 1:1,5, en 1990-1999 y 1:31 después de 2000), mientras que la proporción entre préstamos directos e indirectos es de 35:7, por lo tanto de 5:1, per total (con 7:3, o casi 2,5:1, y 28:4, o 7:1, respectivamente para los dos períodos). El DCSR, por su parte, registra 23 entradas (algunas presentes también en DCR2 o DCR3), de las cuales, 19 con etimología directa (carambola, cava, chorizo, churro, enchilada, gazpacho, granadilla, 
macho, maracas, niño, paella, piña colada, piñata, sangría, tabasco, tapas, telenovelă, tortilla/tortillas), 2 con etimología múltiple, español junto con francés o inglés (cava, tabasco), y 4 con etimología indirecta, a través del francés y el inglés (guacamole, guano, guava, tequila), indicando una proporción de 19:4, o sea de casi 5:1 entre préstamos directos e indirectos; desde otra perspectiva, 10 entradas son adaptadas (cava, guacamole, guano, guava, macho, maracas, niño, tabasco, telenovelă, tequila) y 13 no adaptadas (carambola, chorizo, churro, enchilada, gazpacho, granadilla, paella, piña colada, piñata, sangria, tapas, tortilla/tortillas) per total, en una proporción de 10:13, aproximadamente de 1:1,5, mientras que entre los préstamos directos, probablemente más recientes, 6 son adaptados y 13 no adaptados, en una proporción de 6:13, o sea aproximadamente de 1:2. Los datos convergen entre ellos y a la vez con la evolución sociopolítica reciente, confirmando el contacto directo mucho más intenso entre el español y el rumano especialmente después de 2000: crecen considerablemente tanto el volumen de palabras hispánicas como el procentaje de préstamos directos y de formas no adaptadas.

Los elementos léxicos hispánicos incorporados últimamente al rumano son, en español, patrimoniales o bien de otro origen: italiano (piñata), valenciano (paella), árabe (lima > limetă) y, en mayor número, hispanoamericanas, amerindias (guacamole, guano) o no (merengue, milonga). Por otra parte, la etimología indirecta puede favorecer la llegada de formas periféricas en el ámbito hispánico: avocado (usado en Filipinas, cf. dle.rae.es, entrado por vía del inglés o del francés) frente a aguacate, limetă (diminutivo, entrado a través del francés) frente a lima. Hay a la vez usos de moda, posiblemente pasajeros, por ejemplo, en el deporte, tiki-taka (DCR3), golazo (http://www.ziare.com) y partidazo (en la televisión). Como elemento insólito, el español se infiltra en la jerga rumana, según se refleja en www.123urban.ro: macho, maricon, chancho, mojo, pajero, Maria Ioana ('marihuana', literalmente "Maria Juana"), a avea cojones (calco perfecto de tener cojones), a da (cuiva) la cucaracea ('tener relaciones sexuales', literalmente "dar (a alguien) a la cucaracha", suponemos que siguiendo el modelo de expresiones rumanas como a da (cuiva) la cap, literalmente "dar (a alguien) a la cabeza", 'golpear (a alguien) en la cabeza'; no se registra como entrada separada cucaracea, adaptación de cucaracha, aquí en la acepción vulgar de algunos países de América, cf. http://www.jergasdehablahispana.org). La vulgaridad de algunas palabras o expresiones indica un contacto directo con el español, probablemente por medio de la comunidad rumana de España, mientras que algunos rasgos regionales (chancho, cucaracha, pajero, cf. DLE, dle.rae.es) sugieren el contacto también con variedades americanas del español, mediante los inmigrantes procedentes de Hispanoamérica. 
Los préstamos que aquí interesan son, en general, lexías simples, aunque se observan, de manera inédita, lexías complejas (piña colada) y unidades fraseológicas (a avea cojones), más formas derivadas para palabras existentes en rumano (golazo vs. gol n., partidazo vs. partidă f.). Como categoría gramatical, son mayoritarimente sustantivos, algunos adjetivos o adjetivos/sustantivos (sandinist/- $\breve{a}$, maricon) y adverbios (absolutamente), en la jerga incorporados a veces en locuciones verbales, calcadas (a avea cojones) o no (a da (cuiva) la cucaracea).

En el plano semántico, se trata mayoritariamente de realidades pertenecientes al mundo hispánico, tanto peninsular como ultra-atlántico. Buena parte de estos préstamos están vinculados a Hispanoamérica (burrito, cebiche/ceviche, chili, enchilada, fajita, guacamole, latino, merengue, milonga, quesadilla, telenovelă, tequila); se continúa así la incorporación de palabras de la zona iniciada mucho antes de 1990 a través de traducciones literarias y mass media, ahora además con elementos de la jerga, como se ha mencionado. En ocasiones, los usos latinoamericanos preceden a los ibéricos, al caracterizarse los 90 en Rumanía por las telenovelas y los años 2000 por la emigración en masa a España: para tortilla, la acepción de alimento preparado con huevo, 1 del DLE (dle.rae.es), se registra apenas en el DCSR (2014), mientras que las acepciones hispanoamericanas, de torta de harina de trigo/maíz, 2 y 3 del DLE (dle.rae.es) están atestados en 2003 y 2006 (DCR3). ${ }^{\S \S \S}$ Han entrado voces de la terminología popular y culta (bakalao, maracas, merengue, milonga) o solo sentidos especializados: (El) niño (fenómeno meteorológico, DE); el español contribuye así al enriquecimiento de la terminología rumana. Los dominios semánticos mejor representados son la alimentación (chorizo, enchilada, gazpacho, guacamole, nachos, paella, sangria, tequila, tortilla, avocado, carambola, guano, guava, limetă, maca, mate), la música, el baile y el arte en general (maracas, muralist, milonga, salsa, tiento, tonadilla), la política (contras, sandinist), el deporte (golazo, partidazo, tiki-taka).

La adaptación fonética y ortográfica es variable. Se suele conservar la pronunciación española si tiene correspondencia en rumano, aun cuando la ortografía requería en este una pronunciación diferente, en casos como macho, fajita, tequila, merengue, cebiche/ceviche, hacienda (DCR3). Contribuye probablemente a tal tendencia la importación masiva en el rumano actual de elementos extranjeros, sobre todo ingleses, con la pronunciación y la grafía

\footnotetext{
§§§§ La situación puede cambiar en los años venideros por medio de la comunidad étnica formada en España, que
} ya usa en abundancia palabras y unidades fraseológicas españolas (Nica, op. cit., nota 1). 
originarias, más reglas ortográficas bien distintas de las rumanas. Para los fonemas que no existen en rumano, hay vacilación entre la asimilación a fórmulas próximas y la pronunciación de la lengua fuente. La fricativa interdental $/ \theta /$ se adapta a menudo a la fricativa alveolar $/ \mathrm{s} /$ : hacienda (DCR2; DCR3), chorizo, gazpacho (DCR3). La vibrante múltiple se simplifica, aunque se mantiene la grafía originaria: churros, burrito [r] (DCR3). La nasal palatal /n/ se suele aproximar con la secuencia [ni], formando con la vocal siguiente un hiato: piña colada [ni], niño [ni] (DCSR). La lateral palatal / $\lambda /$ vacila entre aproximarse con una de las secuencias [lj] o [li], formando sea un diptongo sea un hiato con la vocal siguiente; y, más raramente, quedarse sin cambiar: mallorquin [1j] (DOOM2, DEX'09) vs. [li] (DCR3), paella [ $\lambda]$ (DCR2)

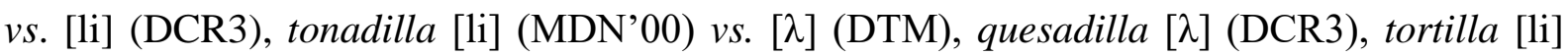
(DCR3, DCRS). La grafía pierde generalmente la tilde. En los nombres propios, se conservan casi sin excepción tanto la ortografía como la pronunciación españolas: El Ferrol del Caudillo $[\lambda](\mathrm{DE})$, Ibáñez $[\mathrm{n}],[\theta](\mathrm{DE})$.

Son notables dos casos de adaptación fonético-morfológica, ya existentes (Sala, 2001, s.v. neologismo): los nombres masculinos en -o y los nombres femeninos en - $a$. La - $a$ átona es impropia en rumano para los nombres femeninos sin artículo, sin embargo, se han incorporado muchos nuevos vocablos hispánicos con esta final sin adaptar (paella, salsa, sangria, tortilla), posiblemente favorecidos por la entrada de otras palabras similares, no solo españolas, sino también italianas (pizza, mozzarella, gorgonzola). Los vocablos del inventario de esta investigación mantienen la $-a$, con la excepción de los muy usados gherilă y telenovelă. La fecha reciente de los préstamos estudiados no permite concluir si se está imponiendo la incorporación con $-a$; la frecuencia de uso puede ser decisiva para la asimilación a - $\breve{a}$, como en el caso de gherilă y telenovelă. Los diccionarios parecen atestar una tendencia hacia la incorporación de estos nombres al género femenino en su paso del español al rumano, pero con algunas excepciones (enchilada n., granadilla n., maracas $\mathrm{n}$., DCSR) o vacilaciones (tapas $\mathrm{f}$. pl., DCR3, vs. tapas n. pl., DCSR). De manera paralela, aunque la -o átona es poco usual en rumano, se va acumulando toda una serie de nombres hispánicos que no la pierden, más antiguos (sombrero, peso, patio) o más recientes (macho, avocado, burrito, chorizo del inventario de este artículo). Si sobreviven a la moda de momento, tampoco parece probable que se adapten formas expresivas como golazo y partidazo. En cuanto al género, aquí puede intervenir en mayor medida el criterio semántico, como se ha mencionado, debido a que en rumano los géneros masculino y neutro comparten terminaciones. Se observa cierta competencia entre el habitual parámetro de animacidad asociado al masculino en rumano y la 
conservación del género masculino español, lo que produce inconsistencias: se respeta el criterio de animacidad para flamenco, guano, tabasco (DCSR), golazo (cf. două golazo 'dos golazos', http://www.gsp.ro), asimilados al neutro, pero se infringe en casos como burrito (DCR2, DCR3), chorizo (DCSR), considerados masculinos, mientras que otros se quedan de momento sin género explícito: balseros, bakalao, gazpacho, churro, coco, nachos (DCR2, DCR3), churro (DCSR). Aun conociendo tratamientos diferentes, avocado tiende a ser categorizado doblemente (DOOM2, DEX'09): masculino ('planta') y neutro ('fruto'), según la regla que diferencia en rumano los árboles de sus frutos a través del género gramatical: masculino vs. femenino/neutro. Para algunos sustantivos los diccionarios no especifican el género: además de los mencionados en -o, es el caso de cava, contras, chili, cebichelceviche, guacamole, mate, merengue, turron (DCR2, DCR3). Quedan por ver las implicaciones mofológicas a largo plazo, si el rumano contará en singular con - o como morfema para el masculino/neutro y con - $a$ para el femenino.

La adaptación en cuanto al número gramatical es igualmente vacilante. Aparecen tanto plurales sigmáticos, a la española (taco-tacos, fajita-fajitas, DCR3), como vocálicos, a la rumana (cerveza-cerveze, sangria-sangrii, DCR3), y en ocasiones dos formas de plural: sing. tortilla-pl.tortilli/tortille (https://dexonline.ro). Hay invariabilidad en varios nombres con -o: coco sg./pl. 'dólar' (mii de coco 'miles de coco', www.123urban.ro), golazo sg./pl. (două golazo 'dos golazos', http://www.gsp.ro), macho sg./pl. (DOOM2), avocado sg./pl. (m./n., DOOM2, 2005), si bien para este último, en neutro, hay indicios de un cambio de norma en curso: avocado sg.-avocadouri pl. (n., MDA2, 2010). Han entrado algunas formas de plural, por ser percebidas como pluralia tantum (nachos, empanadas, tapas, DCR3; llanos, DE, MDN'00, DOOM2). Los supuestos casos de pluralia tantum y el uso dominante de los sentidos de una palabra bien en singular, bien en plural llevan, en ocasiones, a delimitar dos entradas en el diccionario (DCRS): tortilla para alimento preparado con huevo vs. tortillas para torta de harina de trigo/maíz (los sentidos 1 y $2 / 3$ respectivamente del DLE, dle.rae.es).

En lo que concierne a la posposición del artículo definido, muchos préstamos hispánicos recientes no están todavía adaptados y se usan en contextos que no requieren artículo, como enumeraciones, aposiciones, etc. Los nombres que han mantenido la $-a$, asimilados al femenino se emplean con la misma forma en situaciones en que deberían articularse, puesto que esa $a$ final coincide en rumano con el artículo definido del femenino singular: Quesadilla e (...) un aperitiv mexican (...) ‘(La) quesadilla es (...) un entrante mexicano (...)’ (DCR3). Los nombres 
masculinos o neutros, por su parte, pueden tener usos a la española, con plural sigmático y artículo español (los balseros, DCR2), pero también formas articuladas al estilo rumano: machoul, avocadoul (DOOM2).

En el caso de los adjetivos (algunos también sustantivos), las terminaciones similares con las rumanas facilitan la asimilación: mallorquin m. sing., câini mallorquini 'perros malloquinos' m. pl., deșerturile mallorquine 'los desiertos malloquinos' n. pl. (DCR3); sandinist m. sing., sandiniștii m. pl. con artículo definido 'los sandinistas' (DCR3). Los adjetivos en -ista siguen adaptándose con dos formas separadas: -ist m., -istă f. (castristcastristă , DCR2). Hay adjetivos invariables, un comportamiento muy restringido en rumano, posiblemente debido a su paso por el inglés, como latino (muzică latino f. sing., dansuri latino, n. pl., DCR3), o a su uso en plural frecuente en español, como contras (en fuerzas contras, DCR2).

\section{Conclusiones}

Las evoluciones político-sociales de la Rumanía postcomunista han propiciado el contacto lingüistico con el español. Centrándonos en el contacto ocurrido dentro del país, se ha estudiado la entrada en rumano de vocablos hispánicos después de 1990, a partir de un núcleo de 61 unidades léxicas extraídas de varias fuentes, pero ampliando el análisis a un corpus de diccionarios.

Se observa un incremento cuantitativo relativamente importante con respecto a las estimaciones de cerca de 150 palabras en los años 80, aunque se ha analizado un inventario léxico parcial. Dentro del período estudiado, los datos reflejan la acentuación del contacto inmediato después de 2000, a consecuencia de la fuerte emigración desde Rumanía a España, con un notable aumento de préstamos, especialmente directos y no adaptados. Son igualmente muestras de esta situación la aparición, en el contacto, de la jerga y la fraseología, más la multiplicación de los elementos de vida práctica. Los elementos léxicos incorporados recientemente son patrimoniales españoles, amerindios y unos pocos de otro origen. La etimología directa puede ser múltiple: española y, a la vez, francesa, inglesa, italiana o catalana. Los préstamos indirectos se ven a veces afectados por la lengua intermediaria, llegando al rumano formas periféricas en el ámbito hispanohablante o invariables. Es manifiesto un cambio en el tipo de contacto lingüístico: el español es cada vez menos transmitido por vía del francés o del inglés y llega directamente al rumano, incluso es vehículo para otros idiomas. 
Las incorporaciones recientes pertenecen especialmente a los dominios de la alimentación, el arte, la política o el deporte, y enriquecen la terminología rumana, popular o culta. En los últimos años, el español vuelve a ser así una fuente para la modernización y la internacionalización del léxico rumano, contribuyendo a la vez a reforzar el carácter románico de la lengua rumana.

La presente investigación confirma consideraciones previas de la bibliografía sobre la adaptación al rumano de los préstamos en general y en particular de los hispánicos, así como sobre las tendencias actuales observables en el mismo. Si bien la proximidad de los fenómenos estudiados impide decantar conclusiones, se observa la preferencia por la grafía originaria de las incorporaciones recientes; la pronunciación también se mantiene si hay correspondencia en rumano, alternativamente vacila entre la conservación y la aproximación en distintos grados con secuencias sonoras familiares, lo que produce variantes; también es visible la presión hacia la adaptación por parte del sistema gramatical rumano, con la incorporación a los tres géneros, la posposición del artículo, plurales vocálicos, etc. Sin embargo, el proceso de adaptación parece ser disminuido por la existencia previa de algunas fórmulas de asimilación conservadora, el prestigio en aumento del español y el contacto directo con este, sin olvidar el contacto con otros idiomas, como el italiano y especialmente el inglés, abriéndose posiblemente nuevas tendencias en la incorporación de los elementos hispánicos al rumano.

El contacto por medio de la comunidad rumana de España, debido a la dimensión y a la naturaleza diferente -fuera del país, en ambiente alófono y en situación de diglosia-, acentuará la influencia del español también sobre el rumano intraterritorial, tal como los datos analizados sugieren, pero el proceso se podrá evaluar con más claridad a medio y largo plazo.

\section{Bibliografía}

Avram, Mioara. (1982). Contacte între română şi alte limbi romanice. Studii şi cercetări lingvistice, XXXIII (3), 253-259.

Dimitrescu, Florica. (1985). Elementele lexicale romanice recent introduse în limba română. Cercetări lingvistice, XX (2), 105-113.

Dimitrescu, Florica. (1986). Elementele lexicale romanice recent introduse în limba română. Cercetări lingvistice, XXI (1), 9-17. 
Dimitrescu, Florica. (2007a). Despre elementele lexicale latino-romanice recente ale limbii române - considerații cantitative. En Pană Dindelegan (Ed.) (pp. 517-526).

Dimitrescu, Florica. (2007b). Elemente latino-romanice non-franceze în lexicul actual al limbii române. En Reinheimer Rîpeanu y Vintilă-Rădulescu (Eds.) (pp. 113-124).

Dimitrescu, Florica. $\left(2014^{\mathrm{a}}\right.$ ). Teme lexicale actuale (începutul secolului al XXI-lea). București: Editura Academiei Române.

Dimitrescu, Florica. (2014b). Lexicul românesc actual-două tendințe. En Dimitrescu, Teme lexicale actuale (începutul secolului al XXI-lea) (pp. 336-350). București: Editura Academiei Române.

Lăzărescu, Anca Anne-Marie. (2013). Neologismele în presa noastră actuală (cu specială referire la cea scrisă) (Tesis doctoral). Universidad de Bucarest.

Pană Dindelegan, Gabriela (Ed.). (2007). Limba română - Stadiul actual. Omagiu Matilda Caragiu. București.

Reinheimer Rîpeanu, Sanda e Ioana Vintilă-Rădulescu (Ed.). (2007). Omagiu acad. Marius Sala la împlinirea a 75 de ani. București: Editura Academiei Române.

Sala, Marius (Ed.). (2001). Enciclopedia limbii române. Bucureşti: Univers Enciclopedic.

Stăncioi-Scarlat, Mădălina. (2010). Elemente lexicale recente în limba română. Aspecte etimologice (Tesis doctoral). Universidad de Bucarest.

Şandru-Olteanu, Tudora. (1978). Hispanisme lexicale în limba română. Studii şi cercetări lingvistice, XXIX (5), 607-610.

\section{(@) $\odot \Theta \Theta$}

Esta obra está bajo una licencia de Creative Commons Reconocimiento-NoComercial-SinObraDerivada 4.0 Internacional 